\title{
Aerodynamics analysis of electric car UM body surface using computational fluid dynamics
}

\author{
$\operatorname{Mardji}^{1, *}$, Andoko $^{1}$ and Dani Prsetiyo ${ }^{1}$ \\ ${ }^{1}$ Department of Mechanical Engineering, State University of Malang, 65145 Malang Indonesia
}

\begin{abstract}
The body shape that is engineered in such a way will produce fluid flow characteristics that very and greatly affect the function of the shape of the body. However, until now researchers have not been able to find the right solution to diagnose and synthesize flow structures, so that it is done directly through experimental testing [3]. One of them by using the help of a software CFD (Computational Fluid Dynamics) is Ansys 18.1. Fluid Flow Analysis on the surface of the body electric car UM produces several characteristics such as fluid flow which has a significant obstacle, especially on the surface that has a wide surface that causes a flow that causes the flow is red which indicates the velocity of air flowing in that large area obtained maximum velocity air results of $21.1885 \mathrm{~m} / \mathrm{s}$ marked with the color red and velocity minimum of $0.03947 \mathrm{~m} / \mathrm{s}$ marked in blue, other than that when the air flows produce a pressure that produces the maximum pressure received by the body of $79.12 \mathrm{~Pa}$ and the minimum pressure of $-316.1 \mathrm{~Pa}$ and the value of drag coefficient from the car body electric car UM obtained results of 0.46 .
\end{abstract}

\section{Introduction}

Body shape is one reference of the development of a car. The development is intended to find a body shape that has a small resistance or commonly called aerodynamics. Aerodynamics in the vehicle body is the main thing in a vehicle design planning [1]. As the development of the times, the shape of the body always changes. In addition the body is also developed in terms of prisoner [2].

Body shape that is engineered in such a way will produce fluid flow characteristics are different and very influential on the function of the body shape. However, until now researchers have not been able to find an appropriate solution to diagnose and synthesize flow structures, so that it is done directly through experimental testing [3]. One of them by using the help of a software CFD (Computational Fluid Dynamics) is Ansys 18.1.

The purpose of this research is to make the development effort of electric aerodynamic body design with simulation to know the value of drag coefficient, and to know the pattern of airflow around the car body. Car aerodynamics simulations are performed in a wind tunnel defined as a computational domain using Computational Fluid Dynamics (CFD). This analysis is one of several technological solutions for the automotive sector that can be

* Corresponding author: mardji.ft@um.ac.id 
applied for flow analysis experiments on the car body [4]. With the current technological development, there has been a way to see the state of body shape using fluent analysis. The study was conducted using a numerical simulation method using Autodesk Inventor Professional 2018 software for design of UM car electric body model and Ansys Workbench 18.1 to know and predict coefficient drag and drag force. This method has the potential to get accurate data and faster time in the analysis.

\section{Literature review}

\subsection{Aerodynamics}

Aerodynamics is one of science that has a major impact on modern automotive engineering. Aerodynamics deals with the influence of external factors on the observed object, as well as the shape of the object to achieve the desired performance. Strength and aerodynamic coefficients greatly affect the behavior of vehicles on the street [5].

A car that has an Aerodynamic body has many things that affect it, one of which is the amount of resistance or resistance of an object in this case is the air through which is measured with a value expressed by the value of Coefficent Of drag (Cd) [3].

\subsection{CFD (Computational fluid dynamics)}

Computational fluid dynamics (CFD) is one of the branches of fluid mechanics using numerical methods and algorithms to solve and analyze problems that occur in fluid flow. In CFD the use of computers is vital because it has to do millions of calculations to simulate the fluid and gas interactions used in engineering. When we use CFDs with sophisticated hardware support though, we get only an approach. This is one aspect that continues to be addressed in the development of the CFD method [6]. In summary CFD is predicting quantitatively what will happen when fluid flow occurs.

\subsection{Coefficient of drag}

The drag force of pressure or often called drag pressure is part of the direct drag caused by pressure, $\mathrm{P}$, on an object. This drag is often referred to as drag shape because of its very strong dependence on the shape of objects. The pressure drag is a function of the magnitude of the pressure and orientation of the direction of the surface element in which the pressure force operates. These data can be expressed in dimensionless form and the results can be compared appropriately for prototype calculations [7]. Usually the result for a particular shaped object is a drag constants, CD formulated below.

$$
C d=\frac{F d}{1 / 2 \cdot \rho \cdot V^{2} \cdot A}
$$

Information,

$\mathrm{Cd}=$ coefficient of drag

$\mathrm{Fd}=$ Force Drag $(\mathrm{N})$

$\mathrm{P}=\mathrm{O} 2$ fluid density $\left(1,225 \mathrm{~kg} / \mathrm{m}^{3}\right)$

$\mathrm{V}=$ Fluid velocity $(\mathrm{m} / \mathrm{s})$

$\mathrm{A}=$ Front area $\left(\mathrm{m}^{2}\right)$ 


\section{Method}

CFD fluent analysis is performed on every model of body shape to investigate coefficient drag, drag lift, deformation, and safety factor to know the value of drag coefficient, and to know the pattern of airflow around the car body to perform easy and efficient research on various parameters used with the condition design and manufacturing are easy to evaluate. Here is a research flow diagram that researchers do.

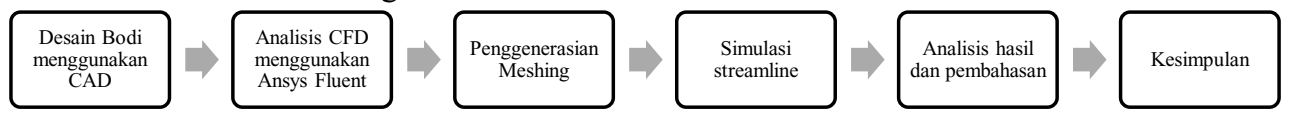

Fig. 1. Research flow diagram.

\subsection{Body shape and vehicle dimensions}
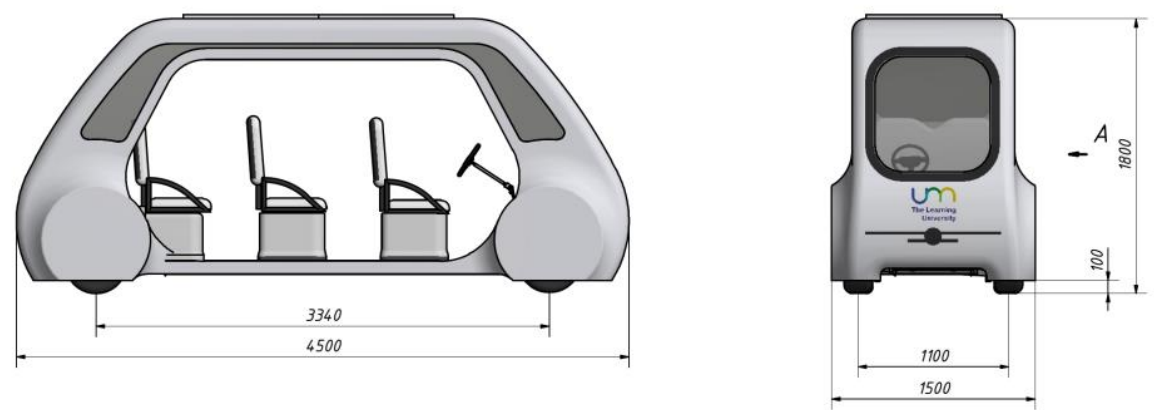

Fig. 2. Body shape and vehicle dimensions.

Table 1. Dimensions of electric Car UM.

\begin{tabular}{|c|c|c|}
\hline No. & Dimensions & Unit (mm) \\
\hline 1. & Lenght & 4500 \\
\hline 2. & Weight & 1500 \\
\hline 3. & High & 1800 \\
\hline 4. & Track Width & 1100 \\
\hline 5. & Whell Base & 3340 \\
\hline 6. & Ground Clearance & 100 \\
\hline
\end{tabular}

Electric car UM body mass can be known from the material properties to be made on the vehicle by taking into account the density and the overall area of the body. Material properties of the body in Molis UM using fiberglass while on the windows made of polycarbonate. After the density is known and the total area of Molis UM body shaping material, the total body mass can be known by the following equation.

Information,

$$
\mathrm{M}=\mathrm{t}\left[\left(\rho_{\mathrm{B}} \times \mathrm{A}_{\mathrm{B}}\right)+\left(\rho_{\mathrm{J}} \times \mathrm{A}_{\mathrm{J}}\right)\right]
$$

$$
\begin{array}{ll}
\mathrm{M} & =\text { Mass Total }(\mathrm{Kg}) \\
\rho_{\mathrm{B}} & =\text { Body Density }\left(\text { fiberglass }=2000 \mathrm{~kg} / \mathrm{m}^{3}\right) \\
\rho_{\mathrm{J}} & =\text { Window Density }\left(\text { polycarbonate }=1200 \mathrm{~kg} / \mathrm{m}^{3}\right) \\
\mathrm{AB}_{\mathrm{B}} & =\text { Area of Body }\left(\mathrm{m}^{2}\right) \\
\mathrm{A}_{\mathrm{J}} & =\text { Window area }\left(\mathrm{m}^{2}\right) \\
\mathrm{t} & =\text { Body thickness }(\mathrm{m}) .
\end{array}
$$


The fiberglass surface area of the Molis UM vehicle body is $13.18 \mathrm{~m} 2$ and the surface area of polycarbonate as window is $2,45 \mathrm{~m} 2$. The total body of the vehicle as a whole has a thickness of $0.003 \mathrm{~m}$, so these values if incorporated into the equation below will produce the vehicle body mass values as follows.

$$
\begin{array}{ll}
\mathrm{M} & =\mathrm{t}\left[\left(\rho_{\mathrm{B}} \times \mathrm{A}_{\mathrm{B}}\right)+\left(\rho_{\mathrm{J}} \mathrm{A} \mathrm{A}_{\mathrm{J}}\right)\right] \\
\mathrm{M} & =0,003[(2000 \times 13,18)+(1200 \times 2,45) \\
\mathrm{M} & =87,93 \mathrm{Kg} .
\end{array}
$$

\subsection{Generating mesh}

After the design of geometry that has been determined by researchers, then performed mesh generation. Mesh generation is done on the meshing menu ANSYS Fluent 18.1 as follows:

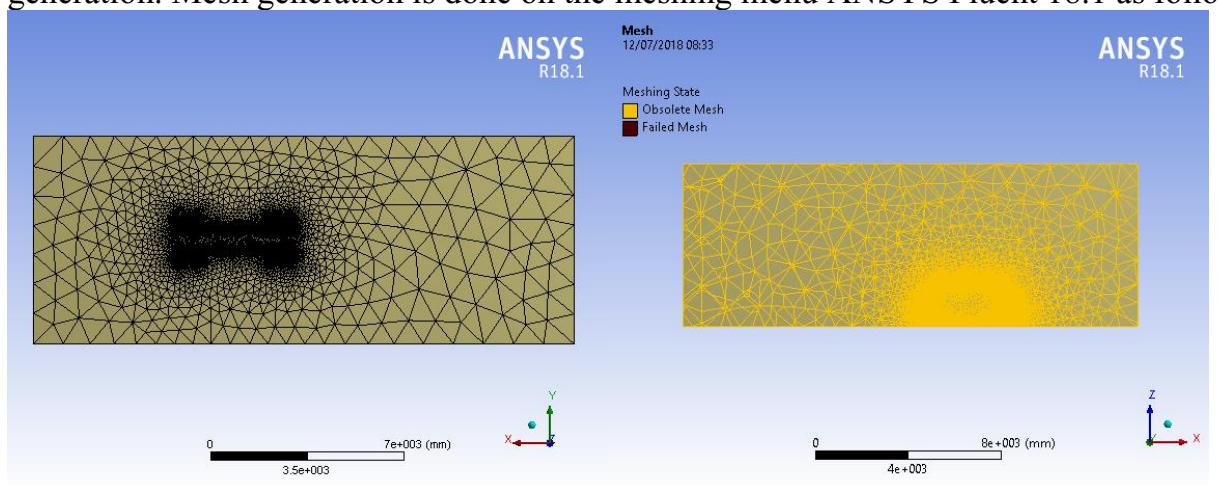

Fig. 3. Meshing.

This process produces mesh 223491 nodes and 1170832 with meduium quality and default skewness of 0.9 .

Table 2. Detail of meshing.

\begin{tabular}{|c|c|c|c|}
\hline No. & Detail of Mesh & Choose & Size \\
\hline 1. & Relevance center & Fine & - \\
\hline 2. & Smoothing & High & - \\
\hline 3. & Transition & Slow & - \\
\hline 4. & $\begin{array}{c}\text { Proximity Size Function } \\
\text { Sources }\end{array}$ & Faces and edges & $\frac{\text { Min size 3.2167mm }}{n}$ \\
& & & $\frac{3.2167 \mathrm{~mm}}{2}$ \\
& & & $\frac{\text { Max face size } 321.67 \mathrm{~mm}}{\text { Max tet size } 643.34 \mathrm{~mm}}$ \\
& & & Growth rate (default) 1.2 \\
\hline
\end{tabular}

\subsection{Parameter Input}

The turbulent model used in this simulation is the realizable turbulent model k-epsilon nonequilibrium wall functions [8]. Discretization method used is second order upwind to get more accurate result with error less than $5 \%$. Table 3 is the input data given to ANSYS Fluent for the type of turbulent model. 
Table 3. Parameter input.

\begin{tabular}{|c|c|c|}
\hline No. & Parameter & Information \\
\hline 1. & Density & $1,225 \mathrm{~kg} / \mathrm{m}^{3}$ \\
\hline 2. & Viscosity & $1,7894.10^{-5} \mathrm{~kg} / \mathrm{m}^{4}$ \\
\hline 3. & Inlet Velocity & $40 \mathrm{~m} / \mathrm{s}$ \\
\hline 4. & Inlet Turbulance intensity & $1 \%$ \\
\hline 5. & Inlet turbulance viscocity ratio & 10 \\
\hline 6. & Outlet turbulance intencity & $5 \%$ \\
\hline 7. & Outlet turbulance viscocity ratio & 10 \\
\hline
\end{tabular}

\section{Result and Disscusion}

\subsection{Result of fluid flow analysis on UM electric car body}

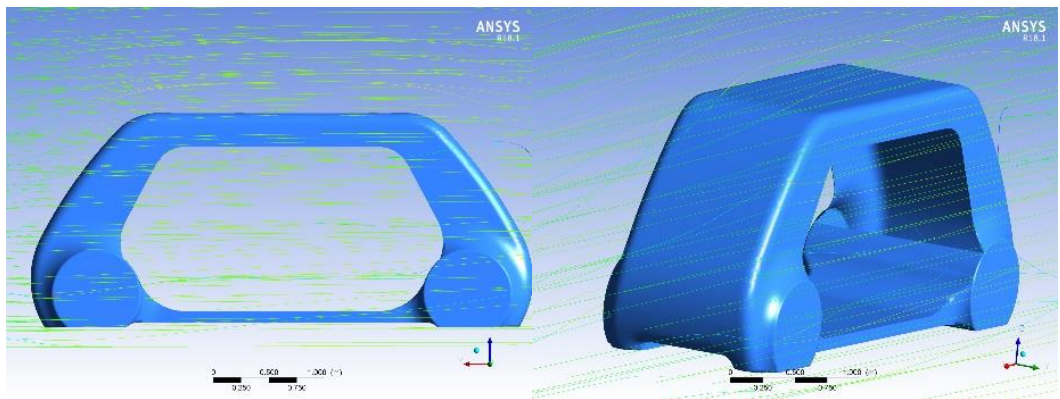

Fig. 4. Fluid flow pattern (streamline) on UM electric car body.

Figure 4 is the result of an analysis showing the existence of some of the inhibited flow as shown in the figure there is a part of the UM Mobil Mobil body which inhibits the rate of fluid flow which in this case the fluid is air.

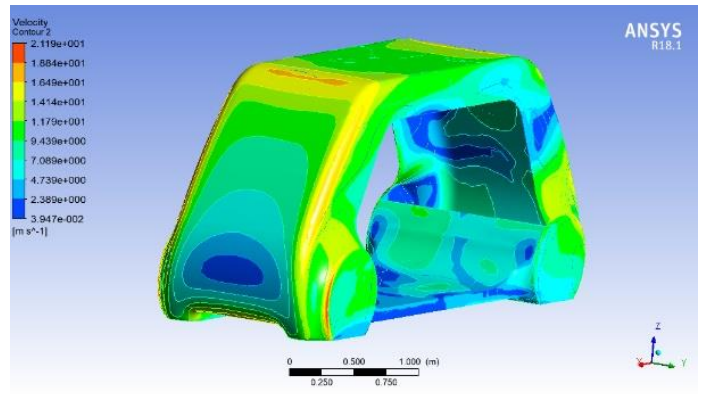

Fig. 5. Velocity of electric car UM.

From the results of the above analysis shows the surface of the body has a different color, where the red color indicates the highest position or position inhibits fluid flow or air flow when flowing in the area. The dark blue color indicates areas where fluid or air travels are the least exposed to air resistance. From the simulation results show by the picture above, velocity max equal to $21.1885 \mathrm{~m} / \mathrm{s}$ with red which is the biggest area provide air resistance, whereas velocity minimum $0,03947 \mathrm{~m} / \mathrm{s}$ with dark blue color which give least air resistance. 
Next when the fluid flow air passes through the UM electric car body, it will produce a pressure received by the body. The analysis results show the pressure obtained by the surface of the body when fluid flowed as shown in figure 6 .

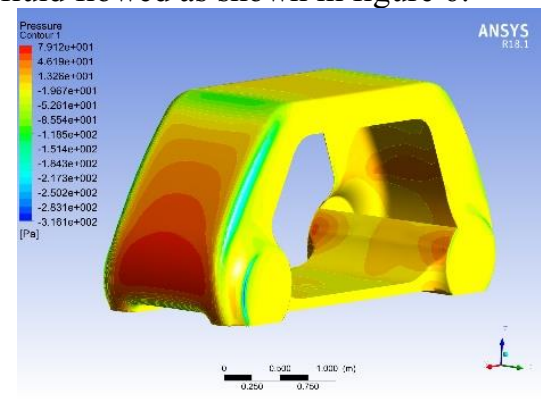

Fig. 6. Pressure of electric car UM body surface.

The results of the simulation above shows the results of pressure analysis that occurs on the surface of the UM electric car body. Maximum pressure is indicated by a red surface or equal to $79.12 \mathrm{~Pa}$ and a minimum pressure of $-316.1 \mathrm{pA}$ or a blue surface.

\subsection{Drag value on UM electric cars}

The drag coefficient is influenced by drag or drag force (Fd), fluid density, fluid velocity and front area [2]. The drag coefficient on the vehicle sutu can be calculated using the following equation.

Information,

$$
C d=\frac{F d}{1 / 2 \cdot \rho \cdot V^{2} \cdot A}
$$

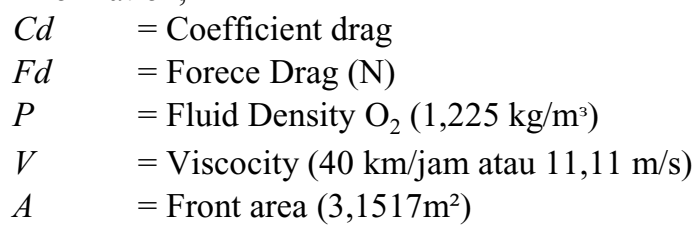

If the value of the analysis on the vehicle is included in the above equation it will get the value of the coefficient of the vehicle as follows.

$$
\begin{aligned}
& C d=\frac{F d}{1 / 2 \cdot \rho \cdot V^{2} \cdot A} \\
& C d=\frac{90 \cdot 7042}{1 / 2 \cdot(1,225) \cdot\left(10^{2}\right) \cdot(3,1517)} \\
& C d=\frac{90,7042}{193,04} \\
& C \boldsymbol{d}=\mathbf{0 , 4 6}
\end{aligned}
$$

\section{Result and Discussion}

Fluid Flow Analysis On the surface of the body UM electric car produces several characteristics diantarnya fluid flow that suffered considerably large, especially on the surface that has a wide surface that causes a flow that causes the flow is red which indicates 
the velocity of air flowing in that large area obtained by the maximum velocity of air of $21.1885 \mathrm{~m} / \mathrm{s}$ marked with red color and minimum velocity of $0.03947 \mathrm{~m} / \mathrm{s}$ marked with blue color, in addition when the air flow produce a pressure that is produce maximum pressure received by the body of $79.12 \mathrm{~Pa}$ and the minimum pressure of $-316,1 \mathrm{~Pa}$ and the Drag Coefficient Value of the UM Electric Car Body is 0.46.

The authors acknowledge to State University of Malang for Hibah Penelitian PNBP UM 2018 with contract number 2.3.175/UN32.14/LT/2018.

\section{References}

1. Buana, W.R.D, et al., Science Article, (2018)

2. Aklis, N, et al., JITM, 16 (2015)

3. Prihadnyana, Y. et al., JJPTM, 8 (2017)

4. Jhon, S.J.S, et al., JTM, 5 (2017)

5. Hidayati, A.N, et al., JEM, 10 (2017)

6. Wardana, E.R., Analysis of Mini-Submarine Obstacles using Testing on a validated Wind Tunnel with Computational Fluid Dynamics. Thesis. ITS. (2015)

7. Siregar, R.M. And Ambarita, H., Journal E-Dinamis ISSN 2338-1035, 3 (2012) 